\title{
CARDIAC FUNCTION AND MUSCULAR OXYGEN DESATURATION IN SPRINT AND ENDURANCE COHORTS DURING THE INCREMENTAL BICYCLE ERGOMETRY
}

\author{
Vilma Papievienè, Kristina Poderienė, Eugenijus Trinkūnas, \\ Albinas Grūnovas, Jonas Poderys \\ Lithuanian Sports University, Kaunas, Lithuania
}

\begin{abstract}
Research background and hypothesis. The objective of this study was to compare the velocity of changes of cardiac output and muscular oxygen desaturation during the graded exercise stress in endurance and sprint cohorts.

Research methods. The subjects, 13 long distance runners and 11 sprinters, underwent a $50 \mathrm{~W}$ increase in workload every 6 minutes and they exercised till the inability to continue the workout. The heart rate (HR), cardiac output and oxygen desaturation $\left(\mathrm{StO}_{2}\right)$ in lateral head of the rectus femoral muscle were registered.

Research results. The averaged values of change in cardiac output at each stage of workout were similar for both cohorts. We found statistically significantly higher velocities of changes in $\mathrm{StO}_{2}$ in the sprint cohort than in the endurance cohort. The lower physical performance abilities are typical of the sprint cohort compared to the endurance cohort but three was no difference between the averaged maximal HR values registered at the end of incremental ergometry. During the exercising with given work rate at stages which became subjectively hard, the $\mathrm{StO}_{2}$ decreased to the same smallest level. This means that the same type of change and the same smallest degree of $\mathrm{StO}_{2}$ occurs just before the inability to continue the exercising.

Discussions and conclusions. The endurance cohort features a more extensive slow augmentation and greater peak values of cardiac output compared to the sprint cohort. The same type of changes and the same degree of muscular oxygen desaturation occur at the point of the inability to continue the exercising, but faster changes in oxygen desaturation in muscular tissue are characteristic of the sprint cohort compared to the sprint cohort.
\end{abstract}

Keywords: bicycle ergometry, cardiac output, oxygen desaturation.

\section{INTRODUCTION}

$\mathrm{P}$ hysical exercise or workload induces a cardiovascular system to increase delivery of oxygen and metabolic substrates to actively contracting skeletal muscles (Bangsbo, Hellsten, 1998; Saltin et al., 1998; Burgomaster et al., 2008; Gibala, 2012). The blood flow to muscles is generally proportional to their metabolic activity (Bangsbo, Hellsten, 1998; Hughson, Tschakovsky, 1999; Burgomaster et al., 2008).

The different effects of training on cardiovascular system undoubtedly reflect adaptations of various factors involved in the regulation of muscle blood flow and delivery of oxygen (Delp, 1998; Burgomaster et al., 2008; Buchheit et al., 2012). A lot of studies of the last years showed high effect of the sprint type of exercising on health benefits and oxygen consumption in muscular tissue (Davison, 2011; Buchheit et al., 2012; Hanon et al., 2012; Hazell et al., 2012). Why are the studies which allow comparing and understanding the peculiarities of acute and chronic effects on endurance and 
sprint training so important? The one important question is how these body functions behave under conditions of increasing fatigue. The objective of this study was to compare the velocity of changes of cardiac output and muscular oxygen desaturation during the graded exercise stress in endurance and sprint cohorts.

\section{RESEARCH METHODS}

The subjects of this study were 13 long distance runners, aged $21.3 \pm 1.31$, body mass index $21.2 \pm$ 0.49 , and 11 sprinters, aged $20.9 \pm 1.15$, body mass index $22.3 \pm 0.32$.

The bicycle ergometric method of incremental increase in workload (graded stress) was used. The subjects underwent a $50 \mathrm{~W}$ increase in workload every 6 minutes (60 revolutions/min) and they exercised it till the inability to continue the task or if the distressing cardiovascular symptoms supervened.

The heart rate and cardiac output were measured with tetrapolar chest rheography (RPG2-02, Medtekhnika, Moscow, Russia), a convenient and bloodless method based on the Kubicek procedure (Pushkar et al., 1977). The stroke volume was calculated from the impedance change information using a formula that relates impedance changes to volume changes in a conducting solid (Kubicek et al., 1966).

Near-infrared spectroscopy (NIRS) was used for the non-invasive monitoring of oxygen desaturation in tissues $\left(\mathrm{StO}_{2}\right)$. The InSpectra Standard System Model 325, which was developed by Hutchinson Technology Inc. (Hutchinson, MN, USA), was used for this purpose. This is a noninvasive monitoring system that was designed to measure an approximated percentage of $\mathrm{StO}^{2}$. A $25 \mathrm{~mm}$ probe spacing (between sending and receiving fibres) on the tissue sample was used. $\mathrm{StO}_{2}$ dynamical changes and recovery were monitored continuously (every $3.5 \mathrm{~s}$ ). The InSpectra sensor was placed on the thigh, on the lateral head of the rectus femoral muscle.

The velocity of changes of registered indices was calculated in percent per one minute, i. e.:

$$
\Delta_{1 \text { min. }}=\left(\mathrm{m}_{\mathrm{n}-} \mathrm{m}_{(\mathrm{n}-1)}\right) / \mathrm{m}_{(\mathrm{n})} * 100,
$$

where $m_{n}$ - value of parameter at the moment, and $\mathrm{m}_{(\mathrm{n}-1)}-$ value of parameter recorded one minute before.
Statistical analysis was performed using the statistical software package SPSS, version 17.0. The recorded variables exhibited parametric and non-parametric distributions. Differences between certain stages were tested using Tukey's HSD test. The level of significance was conducted at $\mathrm{p}<0.05$.

\section{RESEARCH RESULTS}

Figure $1 \mathrm{~A}$ presents the dynamics of HR during the incremental increase in workload. A stepwise increase of HR depends on the work rate. The faster increase of HR was observed in the sprint than in the endurance cohort, but comparing the maximal HR values registered while performing the last stage of workout we found no statistically significant difference between the cohorts $(\mathrm{p}>0.05)$.

The initial values of cardiac output obtained with tetrapolar chest rheography before the exercising was $5.3 \pm 0.6 \mathrm{l} / \mathrm{min}$ in sprint and $6.1 \pm$ $0.4 \mathrm{l} / \mathrm{min}$ in endurance cohorts. The cardiac output intensified depending on the work rate (Figure $2 \mathrm{~B}$ ). The increase of cardiac output while performing the workload had the same tendency of stepwise increase with the each higher stage in both cohorts. This tendency was strongly observable during the first stages of the workout and weakened when exercising became subjectively hard, i.e. during the last stages of the workout. The highest values were registered during the last stages of the workout, i.e. in the endurance cohort up to $31.2 \mathrm{1} / \mathrm{min}$, and in the sprint cohort up to $19.4 \mathrm{l} / \mathrm{min}$.

Dynamics of $\mathrm{StO}_{2}$ during the incremental exercising are presented in Figure 2. The type of curves indicates that these changes depended on the work rate and this was typical of both cohorts. The level to which $\mathrm{StO}_{2}$ decreased when the exercising became subjectively hard was similar for both cohorts. During the recovery after the workload the $\mathrm{StO}_{2}$ increased rapidly.

Velocities of changes of cardiac output and $\mathrm{StO}_{2}$ during the incremental bicycle ergometry are presented in Table. The averaged values of change at each stage of workout were similar for both cohorts when the velocities of changes in cardiac output were compared ( $p>0.05$ ). We found statistically significant higher velocities of changes in $\mathrm{StO}_{2}$ in the sprint cohort than in the endurance cohort ( $p<0.05$, see tinted parts of the Table) while the participants exercised at the stages of $150 \mathrm{~W}$ and $200 \mathrm{~W}$. 
Figure 1. Dynamics of $\mathrm{HR}$ (A) and cardiac output (B) during the incremental increase in workload
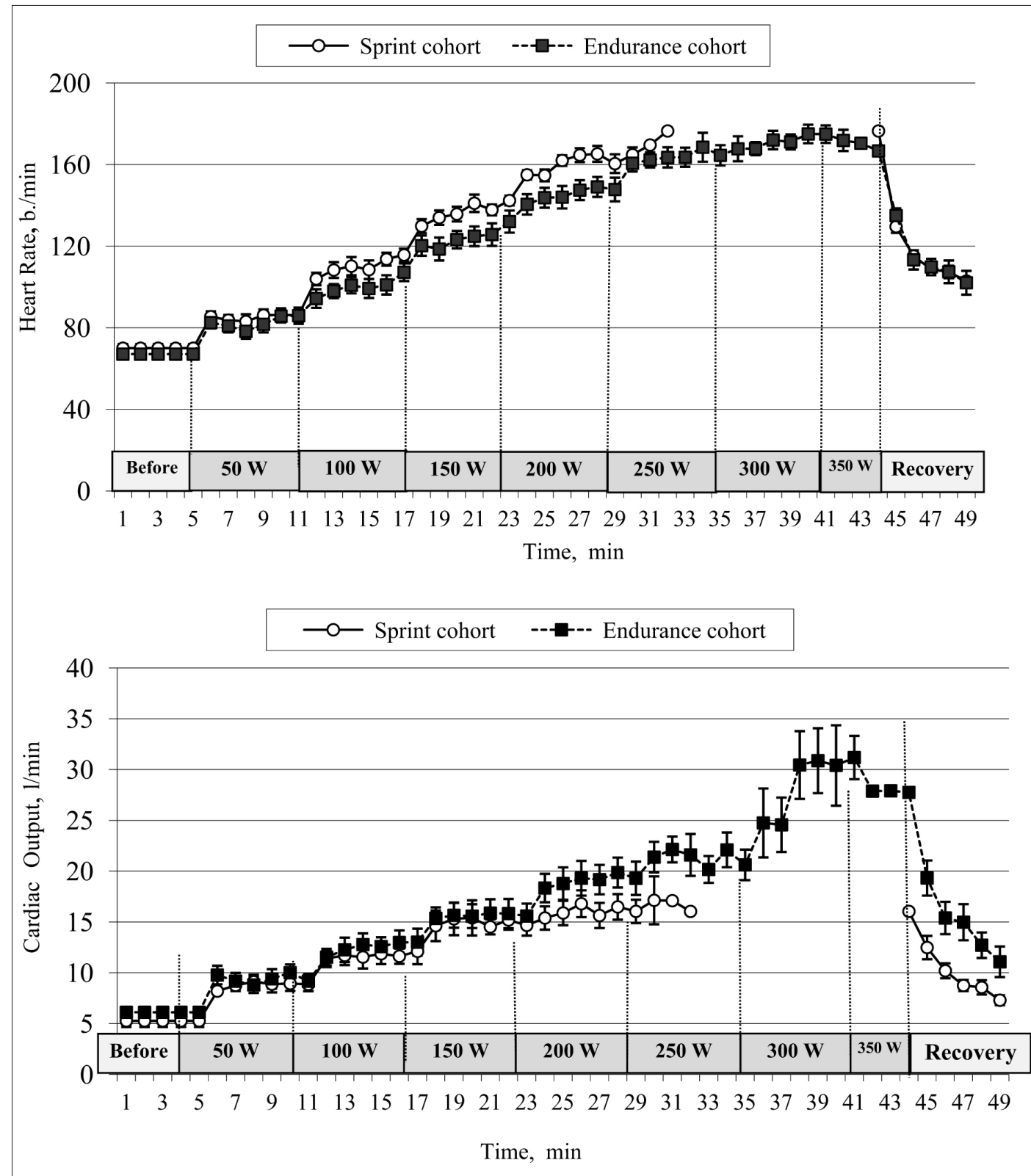

Figure 2. Dynamics of oxygen desaturation $\left(\mathrm{StO}_{2}\right) \mathrm{du}-$ ring the incremental increase in workload

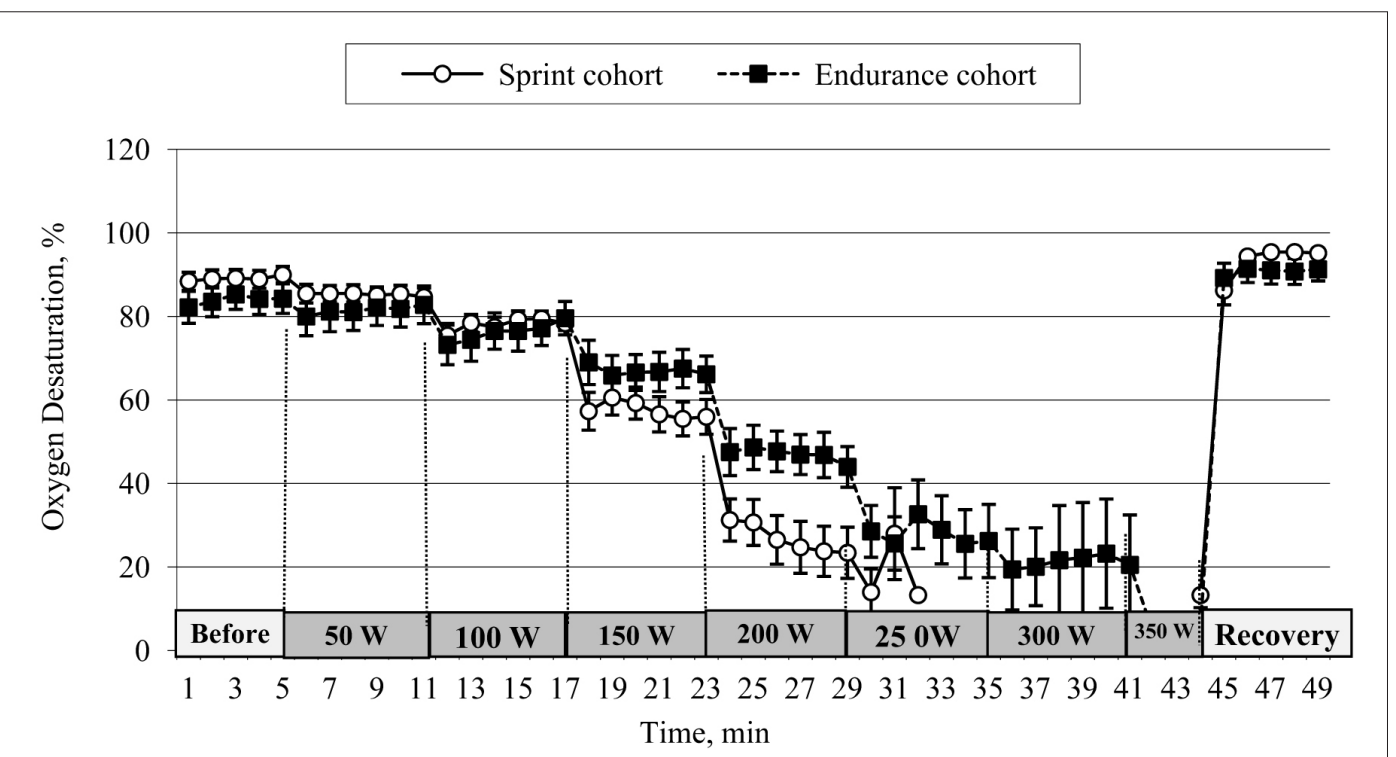




\begin{tabular}{|c|c|c|c|c|c|c|}
\hline \multirow{2}{*}{ Index } & \multirow{2}{*}{ Cohort } & \multicolumn{4}{|c|}{ Stage of incremental exercising } & \multirow{2}{*}{$\begin{array}{l}\text { Table. Velocity of changes of } \\
\text { cardiac output and oxygen } \\
\text { desaturation }\left(\mathrm{StO}_{2}\right) \text { during } \\
\text { incremental bicycle ergo- } \\
\text { metry }\end{array}$} \\
\hline & & $\begin{array}{c}50 \mathrm{~W} \\
1-6 \mathrm{~min}\end{array}$ & $\begin{array}{c}100 \mathrm{~W} \\
6-12 \mathrm{~min}\end{array}$ & $\begin{array}{c}150 \mathrm{~W} \\
12-18 \mathrm{~min}\end{array}$ & $\begin{array}{c}200 \mathrm{~W} \\
18-24 \mathrm{~min}\end{array}$ & \\
\hline \multirow{3}{*}{$\begin{array}{l}\text { Cardiac } \\
\text { output }\end{array}$} & Endurance & $10.3 \pm 0.92$ & $4.5 \pm 0.84$ & $3.5 \pm 0.86$ & $3.1 \pm 0.81$ & \\
\hline & Sprint & $9.4 \pm 1.03$ & $4.9 \pm 0.92$ & $4.1 \pm 0.93$ & $2.0 \pm 1.01$ & \\
\hline & $\begin{array}{l}\text { Difference between } \\
\text { cohorts }\end{array}$ & $\mathrm{p}>0.05$ & $\mathrm{p}>0.05$ & $\mathrm{p}>0.05$ & $\mathrm{p}>0.05$ & \\
\hline \multirow{3}{*}{$\mathrm{StO}_{2}$} & Endurance & $0.09 \pm 0.48$ & $2.1 \pm 0.52$ & $2.4 \pm 0.68$ & $4.7 \pm 0.64$ & \\
\hline & Sprint & $0.09 \pm 0.51$ & $2.0 \pm 0.55$ & $4.7 \pm 0.68$ & $7.8 \pm 0.69$ & \multirow[b]{2}{*}{$\begin{array}{l}\text { Note. The values in Table are } \\
\text { given in percent per one min- } \\
\text { ute. }\end{array}$} \\
\hline & $\begin{array}{l}\text { Difference between } \\
\text { cohorts }\end{array}$ & $\mathrm{p}>0.05$ & $\mathrm{p}>0.05$ & $\mathrm{p}<0.05$ & $\mathrm{p}<0.05$ & \\
\hline
\end{tabular}

\section{DISCUSSION}

The bicycle ergometric workload which was used in our investigation engaged a large muscle mass, so the functional capacity of the cardiovascular system plays an important role (Saltin et al., 1998; Burgomaster et al., 2008). It is the capacity of "resistance vessels" to alter dramatically their internal diameter that provides a rapid and effective means for regulating blood flow through the peripheral vasculature (Saltin et al., 1998; Hughson, Tschakovsky, 1999). During exercise at $\mathrm{VO}_{2}$ max, approximately $85 \%$ of cardiac output is directed toward the skeletal muscle (Rowel, 1993). Thus, an intense arterial circulation in active muscles is a good condition for the delivery of oxygen and metabolic substrates to, as well as removal of metabolic by-products and heat from actively contracting muscles (Delp, 1998). Blood flow increases in proportion to the intensity of exercise (Saltin et al., 1998) and these changes in muscle blood flow influence directly the intensity of oxidative metabolic processes (Bangsbo, Hellsten, 1998; Joyner, Proctor, 1999; Amann, Calbet, 2008).

The results obtained during this study showed a well-known feature of lower physical performance abilities of the sprint cohort in bicycle ergometry compared to the endurance trained athletes (Delp, 1996; Saltin et al., 1998; Gibala et al., 2012). The higher cardiac performance is one of the causes of that as it was shown during this study. The endurance cohort features a more extensive slow augmentation and greater peak values of cardiac output compared to the sprint cohort. We found statistically significantly higher velocities of changes in $\mathrm{StO}_{2}$ in the sprint cohort while the participants of this study exercised at the stages of $150 \mathrm{~W}$ and $200 \mathrm{~W}$. These two last stages were subjectively hard to all participants of the sprint cohort and only for a few participants form the endurance cohort, i. e. all of them were unable to continue the task. The majority of subjects from the endurance cohort demonstrated higher performance abilities, i. e. they exercised even at the stages of $250 \mathrm{~W}$ and $300 \mathrm{~W}$, and namely at this moment $\mathrm{StO}_{2}$ decreased to the same lowest level. This means that the same type of changes and the same smallest degree of $\mathrm{StO}_{2}$ occur just before the moment of inability to continue the exercising. This correspond to the statement that work efficiency in humans is relatively fixed for a given work task (Wasserman et al., 2004), i. e. the slope of the relationship between oxygen consumption and cycle ergometer rate is approximately the same for all normal people.

\section{CONCLUSIONS}

1. The lower physical performance abilities are typical of the sprint cohort compared to the endurance cohort, but there were no differences between the averaged maximal HR values registered at the end of incremental ergometry.

2. The endurance cohort featured a more extensive slow augmentation and greater peak values of cardiac output compared to the sprint cohort.

3. The same type of changes and the same degree of muscular oxygen desaturation occur at the point of the inability to continue the exercising, but faster changes in oxygen desaturation in muscular tissue are characteristic of the sprint cohort compared to the endurance. 


\section{REFERENCES}

Amann, M., Calbet, J. A. (2008). Convective oxygen transport and fatique. Journal of Applied Physiology, 104, 861-870

Bangsbo, J., Hellsten, Y. (1998). Muscle blood flow and oxygen uptake in recovery from exercise. Acta Physiologica Scandinavica, 162 (3), 305-312.

Buchheit, M., Abbiss, C. R., Peiffer, J. J., Laursen, P. B. (2012). Performance and physiological responses during a sprint interval training session: Relationships with muscle oxygenation and pulmonary oxygen uptake kinetics. European Journal of Applied Physiology, 112 (2), 767-779.

Burgomaster, K. A., Howarth, K. R., Phillips, S. M. et al. (2008). Similar metabolic adaptations during exercise after low volume sprint interval and traditional endurance training in humans. The Journal of Physiology, 586 (1), 151-160.

Davison, G. (2011). Innate immune responses to a single session of sprint interval training. Journal of Applied Physiology, Nutrition, and Metabolism, 36 (3), 395-404.

Delp, M. D. (1998). Differential effects of training on the control of skeletal muscle perfusion. Medicine \& Science in Sports \& Exercise, 30 (3), 361-374.

Gibala, M. J., Little, J. P., Macdonald, M. J., Hawley, J. A. (2012). Physiological adaptations to low-volume, highintensity interval training in health and disease. The Journal of Physiology, 1 (590), 1077-1084.

Hanon, C. I., Bernard, O., Rabate, M., Claire, T. J. (2012). Effect of two different long-sprint training regimens on sprint performance and associated metabolic responses. Journal of Strength and Conditioning Research, 26 (6), 1551-1557.

Hazell, T. J., Olver, T. D., Hamilton, C. D., Lemon, P. W. R. (2012). Two minutes of sprint-interval exercise elicits 24-hr oxygen consumption similar to that of $30 \mathrm{~min}$ of continuous endurance exercise. International Journal of Sport Nutrition and Exercise Metabolism, 22 (4), 276-283.

Hughson, R. L., Tschakovsky, M. E. (1999). Cardiovascular dynamics at the onset of exercise. Medicine \& Science in Sports \& Exercise, 31 (7), 10051010.

Joyner, M. J., Proctor, D. N. (1999). Muscle blood flow during exercise: The limits of reductionism. Medicine \& Science in Sports \& Exercise, 31 (7), 1036-1040.

Knight, D. R., Poole, D. C., Hogan, M. C., Bebout, D. E., Wagner, P. D. (1996). Effect of inspired $\mathrm{O}_{2}$ concentration on leg lactate release during incremental exercise. Journal of Applied Physiology, 81 (1), 246-251.

Kubicek, W. G., Karnegis, J. N., Patterson, R. P., Witsoe, D. A., Matson, R. H. (1966). Development and evaluation of an impedance cardiac output system. Aerospace Medicine, 37, 1208-1212.

Poderys, J. (1998). Application of methods for increasing muscle blood flow intensity during worming-up. Journal of Sports Science, 5, 88-90.

Pushkar, I. T., Bol'shov, V. M., Elizarova, N. A., Kukharchuk, V.V., Tsvetkov, A.A. (1977). Determination of cardiac output by the method of tetrapolar chest rheography and evaluation of its metrological possibilities (in Russian). Kardiologija, 17, 85-90.

Rowel, L. B. (1993). Human Cardiovascular Control. New York: Oxford Press.

Saltin, B., Radegran, G., Koskolou, M. D., Roach, R. C. (1998). Skeletal muscle blood flow in humans and its regulation during exercise. Acta Physiologica Scandinavica, 162 (3), 421-436.

Wasserman, K., Hansen, J. E., Sue, D. Y., Stringer, W. W., Whipp, B. J. (2004). Principles of Exercise testing and Interpretation. Including Pathophysiology and Clinical Applications. Lippincott Williams \& Wilkins. 